\title{
SONOGRAPHIC EVALUATION OF SHOULDER JOINT PAIN WITH MRI CORRELATION
}

\author{
Ramakrishna Narra1, Varunya Mary Jehendren², Johny Prasad Bollipo 3 , Anusha Putcha ${ }^{4}$
}

${ }^{1}$ Associate Professor, Department of Radiodiagnosis, Katuri Medical College, Chinnakondrupadu, Guntur. ${ }^{2}$ Senior Resident, Department of Radiodiagnosis, Katuri Medical College, Chinnakondrupadu, Guntur.

${ }^{3}$ Assistant Professor, Department of Radiodiagnosis, Katuri Medical College, Chinnakondrupadu, Guntur. ${ }^{4} J u n i o r$ Resident, Department of Radiodiagnosis, Katuri Medical College, Chinnakondrupadu, Guntur.

\section{ABSTRACT}

\section{BACKGROUND}

Shoulder pain is one of the most common complaints encountered in clinical practice. It is also the commonest musculoskeletal ultrasound examination request. It often leads to considerable disability, hence an early diagnosis allows proper surgical treatment planning that can prevent functional impairment. Magnetic Resonance Imaging (MRI) is the state of the art diagnostic tool for evaluation of the shoulder. It allows the evaluation of the bone marrow, tendons, muscles, ligaments, capsules and bursae, but its limitations lie in the evaluation of the labrum and glenohumeral ligaments for which MRI arthrography is the study of choice. Improvement in the resolution of USG machines, refined techniques and better understanding of the pathology have contributed to high accuracy in the diagnosis of rotator cuff pathology. With an experienced sonologist and good equipment, accuracy of USG equals that of MRI for full-thickness tears and is slightly better than MRI for partial-thickness tears. USG's real-time capability, low cost and dynamic nature makes it the preferred imaging modality over MRI in several institutes.

\section{MATERIALS AND METHODS}

The present study is a case series study carried out at Katuri Medical College and Hospital in the Department of Radiodiagnosis and includes 50 patients with the complaint of shoulder joint pain with suspected rotator cuff pathologies, were evaluated $p$ with ultrasound examination which was further followed by MRI and the results were compared and analysed for significance. Machines used- USG-Philips Envisor, GE LOGIQ F8, MRI- GE 0.2 Tesla machine.

\section{RESULTS}

50 patients with shoulder pain with a clinical suspicion of rotator cuff tear were evaluated. USG examination of the affected shoulder was done in comparison with the normal shoulder and the findings were correlated with the subsequent MRI findings. Ultrasound can be used for the initial investigation of suspected rotator cuff pathologies. Advantages of ultrasound are noninvasive, real time, low cost, no radiation and the advantage of dynamic examination and comparison with the normal side.

\section{CONCLUSION}

In our study of 50 patients with suspected rotator cuff pathology, ultrasound demonstrated a high sensitivity and specificity more so for supraspinatus tendon pathologies and least for peribicipital tendon fluid collection and SASD bursitis. Also USG is a reliable dynamic diagnostic tool and provides direct correlation of the imaging findings with the symptoms of the patient, and helps with guided interventional procedures. Therefore, it should be considered as an accurate modality for the initial investigation of rotator cuff, especially supraspinatus tears. MRI is preferably done after sonography in doubtful cases or for evaluation of shoulder pathologies like labral tears.

\section{KEYWORDS}

Shoulder Joint, MRI, Ultrasound, Rotator Cuff, Tendons.

HOW TO CITE THIS ARTICLE: Narra R, Jehendren VM, Bollipo JP, et al. Sonographic evaluation of shoulder joint pain with MRI correlation. J. Evolution Med. Dent. Sci. 2017;6(37):3007-3013, DOI: 10.14260/Jemds/2017/649

\section{BACKGROUND}

Shoulder pain is one of the most common complaints encountered in clinical practice. It is also the commonest musculoskeletal ultrasound examination request. It often leads to considerable disability; hence an early diagnosis allows proper surgical treatment planning that can prevent functional impairment.

Financial or Other, Competing Interest: None.

Submission 18-03-2017, Peer Review 24-04-2017,

Acceptance 01-05-2017, Published 08-05-2017.

Corresponding Author:

Dr. Ramakrishna Narra,

Flat No. 30, 5 Floor,

Venkatesh Estate Apartment,

$1 / 2$ Chandramouli Nagar,

Guntur-522006, Andhra Pradesh.

E-mail: narra.ramki29@gmail.com

DOI: $10.14260 /$ jemds $/ 2017 / 649$

\section{(c) $\bigcirc($ ) $९$}

Rotator cuff disease may result from a variety of causes including degenerative, repetitive overhead activities at work or through involvement in sports or due to trauma. The most common causes of a painful shoulder include periarticular soft tissue lesions involving tendons and bursae and are often associated with chronic impingement of the rotator cuff on the anterolateral margin of the acromion. Magnetic Resonance Imaging (MRI) is the state-of-the-art diagnostic tool for evaluation of the shoulder. It allows the evaluation of the bone marrow, tendons, muscles, ligaments, capsules and bursae, but its limitations lie in the evaluation of the labrum and glenohumeral ligaments for which MRI arthrography is the study of choice.

Improvement in the resolution of USG machines, refined techniques and better understanding of the pathology have contributed to high accuracy in the diagnosis of rotator cuff pathology. With an experienced sonologist and good equipment, accuracy of USG equals that of MRI for full- 
thickness tears and is slightly better than MRI for partialthickness tears. USG's real-time capability, low cost and dynamic nature makes it the preferred imaging modality over MRI in several institutes.

\section{Aims and Objectives}

- Evaluation of shoulder joint pain with USG as the first line of imaging emphasising on rotator cuff pathology.

- Correlation of the accuracy of USG with that of MRI in the evaluation of rotator cuff pathologies.

- To delineate pitfalls and limitation of USG when compared with MRI during image interpretation of rotator cuff pathologies in a patient with shoulder pain.

\section{MATERIALS AND METHODS}

The present study was a case series study carried out at Katuri Medical College and Hospital in the Department of Radiodiagnosis, which included 50 patients with the complaint of shoulder joint pain with suspected rotator cuff pathologies who were evaluated with ultrasound examination, which was further followed by MRI and the results were compared and analysed for significance. The following inclusion and exclusion criteria were taken into confidence.

\section{Inclusion Criteria}

The study includes,

- All patients with shoulder pain with a clinical suspicion of rotator cuff injuries.

- All age groups irrespective of sex.

\section{Exclusion Criteria}

The study excludes,

- Patient having history of previous surgery with placement of prosthesis, cardiac pacemakers and metallic foreign body in situ.

- Patient having history of claustrophobia.

- Known cases of rheumatoid arthritis.

Machines Used

USG- Philips Envisor, GE LOGIQ F8.

MRI- GE 0.2 Tesla machine.

\section{Ultrasound Technique}

Shoulder ultrasound was performed using a high frequency (5 - $12 \mathrm{MHz}$ ) linear array probe with tissue harmonic imaging. Patient was made to sit on a rotating stool facing the examiner close to the USG machine. Both static and dynamic assessment of the affected shoulder in comparison with the normal shoulder was done.

The following structures were examined: Biceps tendon, subscapularis, supraspinatus (including test for impingement), infraspinatus, teres minor, posterior glenoid labrum and glenohumeral space, coracoacromial ligament and finally the acromioclavicular joint.

\section{MRI}

Imaging was done with 0.2 Tesla GE machine using shoulder coil. The following sequences were selected as required.

- Coronal oblique T1W/ PD Fast Spin Echo (FSE) sequence.

Coronal oblique STIR sequence.

- $\quad$ Sagittal oblique T2W FSE sequence.
- Axial T2WI.

- Axial PDW FSE.

- Field of view $20 \times 20 \mathrm{~cm}$, slice thickness $4 \mathrm{~mm}$ and matrix- $256 \times 160$.

\section{Statistical Methods}

Significance is assessed at $5 \%$ level of significance. Spearman correlation and Kappa coefficient has been used to find the significance of study parameters on categorical scale between two or more groups. Diagnostic statistics like Sensitivity, Specificity, PPV, NPV and Accuracy have been computed to find the correlation of USG with MRI findings.

\section{RESULTS}

50 patients with the complaint of shoulder joint pain were evaluated using ultrasound, which was further followed by MRI.

\begin{tabular}{|c|c|c|c|c|}
\hline Age & Male & Female & Total & Percentage \\
\hline $21-30$ & 3 & 1 & 4 & 8 \\
\hline $31-40$ & 3 & 4 & 7 & 14 \\
\hline $41-50$ & 11 & 4 & 15 & 30 \\
\hline $51-60$ & 13 & 6 & 19 & 38 \\
\hline $61-70$ & 3 & 0 & 3 & 6 \\
\hline $71-80$ & 1 & 1 & 2 & 4 \\
\hline \multicolumn{5}{|c|}{ Table 1. Age Distribution } \\
\hline
\end{tabular}

\begin{tabular}{|c|c|c|}
\hline Gender & $\begin{array}{c}\text { Number of } \\
\text { Patients }\end{array}$ & Percentage \\
\hline Male & 34 & 68 \\
\hline Female & 16 & 32 \\
\hline Total & $\mathbf{5 0}$ & $\mathbf{1 0 0}$ \\
\hline \multicolumn{3}{|c|}{ Table 2. Gender Distribution } \\
\hline
\end{tabular}

\begin{tabular}{|c|c|c|c|c|c|}
\hline 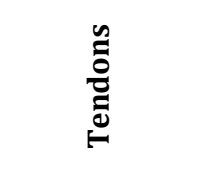 & 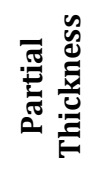 & 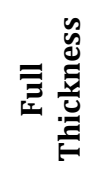 & 密 & 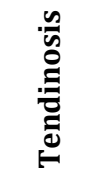 & 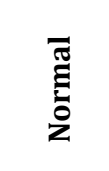 \\
\hline Subscapularis & $\begin{array}{c}02 \\
(4 \%)\end{array}$ & 0 & 0 & 0 & $\begin{array}{c}48 \\
(96 \%)\end{array}$ \\
\hline Supraspinatus & $\begin{array}{c}20 \\
(40 \%)\end{array}$ & $\begin{array}{c}9 \\
(18 \%)\end{array}$ & 0 & $\begin{array}{c}7 \\
(14 \%)\end{array}$ & $\begin{array}{c}14 \\
(28 \%)\end{array}$ \\
\hline Infraspinatus & 0 & 0 & 0 & 0 & $\begin{array}{c}50 \\
(100 \%)\end{array}$ \\
\hline Teres Minor & 0 & 0 & 0 & 0 & $\begin{array}{c}50 \\
(100 \%)\end{array}$ \\
\hline Biceps & 0 & 0 & 0 & $\begin{array}{c}3 \\
(6 \%)\end{array}$ & $\begin{array}{c}47 \\
(94 \%)\end{array}$ \\
\hline
\end{tabular}

Table 3. Ultrasound Findings- Pathology (Tears)

\begin{tabular}{|c|c|c|}
\hline Criteria & Number of Patients & $\mathbf{\%}$ \\
\hline Present & 20 & 40 \\
\hline Absent & 30 & 60 \\
\hline \multicolumn{2}{|c|}{ Table 4. USG Finding of Peribicipital Tendon Fluid } \\
\hline
\end{tabular}

\begin{tabular}{|c|c|c|c|}
\hline $\begin{array}{c}\text { Bursal Fluid/ } \\
\text { Bursitis }\end{array}$ & Criteria & $\begin{array}{c}\text { Number of } \\
\text { Patients }\end{array}$ & $\mathbf{\%}$ \\
\hline \multirow{2}{*}{ SASD } & Absent & 40 & $80 \%$ \\
\cline { 2 - 4 } & Present & 10 & $20 \%$ \\
\hline \multicolumn{3}{|c|}{ Table 5. Ultrasound Findings- Bursal Fluid/Bursitis } \\
\hline
\end{tabular}




\begin{tabular}{|c|c|c|c|c|c|}
\hline$\frac{n}{0}$ & 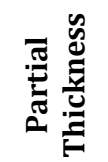 & 离兽 & 悹 & 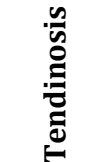 & בే \\
\hline Subscapularis & $\begin{array}{c}2 \\
(4 \%)\end{array}$ & 0 & 0 & $\begin{array}{c}1 \\
(2 \%)\end{array}$ & $\begin{array}{c}47 \\
(94 \%)\end{array}$ \\
\hline Supraspinatus & $\begin{array}{c}25 \\
(50 \%)\end{array}$ & $\begin{array}{c}7 \\
(14 \%)\end{array}$ & 0 & $\begin{array}{c}7 \\
(14 \%)\end{array}$ & $\begin{array}{c}11 \\
(22 \%)\end{array}$ \\
\hline Infraspinatus & 0 & 0 & 0 & 0 & $\begin{array}{c}50 \\
(100 \%)\end{array}$ \\
\hline Teres Minor & 0 & 0 & 0 & 0 & $\begin{array}{c}50 \\
(100 \%)\end{array}$ \\
\hline Biceps & 0 & 0 & 0 & $\begin{array}{c}3 \\
(6 \%)\end{array}$ & $\begin{array}{c}47 \\
(94 \%)\end{array}$ \\
\hline \multicolumn{6}{|c|}{ Table 6. MRI Findings of Tendon Tears } \\
\hline
\end{tabular}

\begin{tabular}{|c|c|c|}
\hline Criteria & $\begin{array}{c}\text { Number of } \\
\text { Patients }\end{array}$ & \% \\
\hline Present & 39 & 78 \\
\hline Absent & 11 & 22 \\
\hline Table 7. MRI Findings- Peribicipital Tendon Fluid \\
\hline
\end{tabular}

\begin{tabular}{|c|c|c|}
\hline Other Findings & $\begin{array}{c}\text { No. of } \\
\text { Patients }\end{array}$ & Percentage \\
\hline No Other Findings (NIL) & 46 & 92 \\
\hline Spinoglenoid Notch Cyst (SGC) & 1 & 2 \\
\hline Calcification in Tendon (CA) & 1 & 2 \\
\hline $\begin{array}{c}\text { Axillary Lymphadenopathy } \\
\text { (AX.LAD) }\end{array}$ & 2 & 4 \\
\hline \multicolumn{2}{|c|}{ Table 8. MRI other Findings } \\
\hline
\end{tabular}

\begin{tabular}{|c|c|c|c|c|c|c|c|}
\hline Sl. No. & Pathology & TP & FP & FN & TN & Detection Rate by USG & Detection Rate by MRI \\
\hline 1 & Subscapularis & 1 & 1 & 1 & 47 & $4 \%$ & $4 \%$ \\
\hline 2 & Supraspinatus & 35 & 0 & 3 & 12 & $70 \%$ & $76 \%$ \\
\hline 3 & Infraspinatus & 0 & 0 & 0 & 50 & $0 \%$ & $0 \%$ \\
\hline 4 & Teres Minor & 0 & 0 & 0 & 50 & $0 \%$ & $0 \%$ \\
\hline 5 & Biceps Tendon & 2 & 1 & 1 & 46 & $6 \%$ & $70 \%$ \\
\hline 6 & Peribicipital Tendon Fluid & 20 & 0 & 19 & 11 & $40 \%$ & $56 \%$ \\
\hline 7 & SASD Bursitis & 7 & 3 & 21 & 19 & $20 \%$ & $78 \%$ \\
\hline \multicolumn{7}{|c|}{ Table 9. Correlation of USG and MRI Findings } & \\
\hline
\end{tabular}

\begin{tabular}{|c|c|c|c|c|c|c|c|c|}
\hline Sl. No. & Pathology & Sensitivity & Specificity & PPV & NPV & Accuracy & P Value by Spearman & Kappa Coefficient \\
\hline & & & & & & & Correlation & Values and Agreement \\
\hline 1 & Subscapularis & $50 \%$ & $97.92 \%$ & $50 \%$ & $97.92 \%$ & $94 \%$ & $\begin{array}{c}<0.001 \\
\text { Significant }\end{array}$ & $\begin{array}{c}0.315 \\
\text { Fair }\end{array}$ \\
\hline 2 & Supraspinatus & $92.11 \%$ & $100 \%$ & $100 \%$ & $80 \%$ & $94 \%$ & $\begin{array}{c}<001 \\
\text { Significant }\end{array}$ & $\begin{array}{c}0.848 \\
\text { Almost Perfect }\end{array}$ \\
\hline 3 & Infraspinatus & - & $100 \%$ & - & $100 \%$ & $100 \%$ & - & - \\
\hline 4 & Teres Minor & - & $100 \%$ & - & $100 \%$ & $100 \%$ & - & 0.645 Substantial \\
\hline 5 & Biceps Tendon & $66.67 \%$ & $97.87 \%$ & $66.67 \%$ & $97.87 \%$ & $96 \%$ & $<0.001$ Significant & $\begin{array}{c}0.012 \\
\text { Significant }\end{array}$ \\
\hline 6 & $\begin{array}{c}\text { Peribicipital } \\
\text { Tendon Fluid }\end{array}$ & $51.28 \%$ & $100 \%$ & $100 \%$ & $\begin{array}{c}36.67 \\
\%\end{array}$ & $62 \%$ & $\begin{array}{c}0.119 \\
\text { Fair }\end{array}$ \\
\hline 7 & $\begin{array}{c}\text { SASD } \\
\text { Bursitis }\end{array}$ & $25 \%$ & $86.36 \%$ & $70 \%$ & $\begin{array}{c}47.5 \\
\%\end{array}$ & $52 \%$ & $\begin{array}{c}\text { Non-Significant } \\
\text { Slight }\end{array}$ \\
\hline \multicolumn{7}{|c|}{ Table 10. Correlation of USG with MRI Findings- Statistical Significance } \\
\hline
\end{tabular}

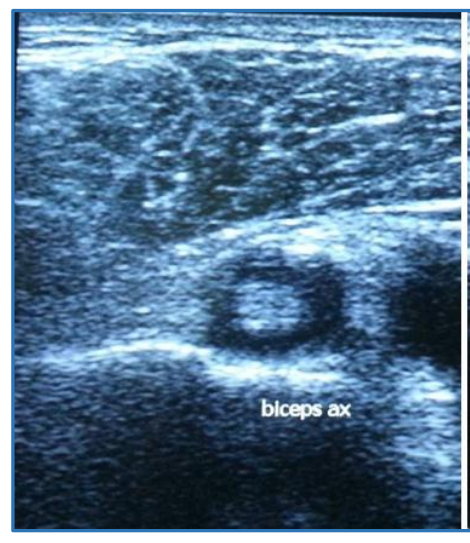

Figure 1. USG Axial and Longitudinal Views of Biceps

Tendon showing Peribicipital Fluid Collection (Arrows)

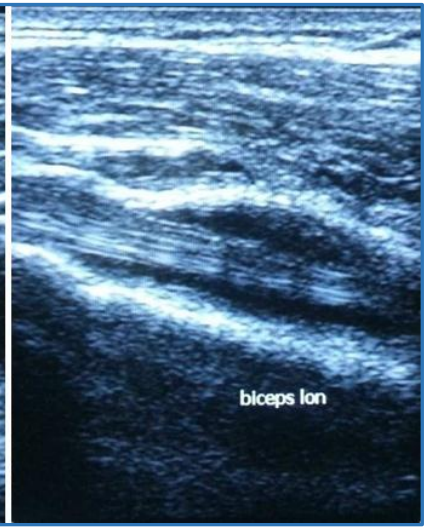

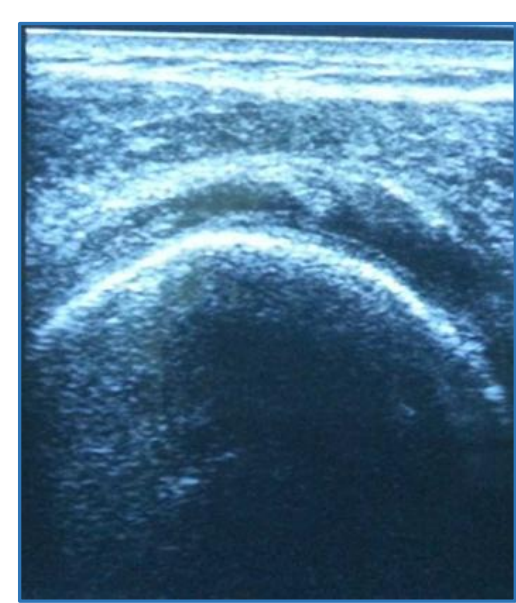

Figure 2. USG Supraspinatus Tendon showing Partial Thickness Tears 


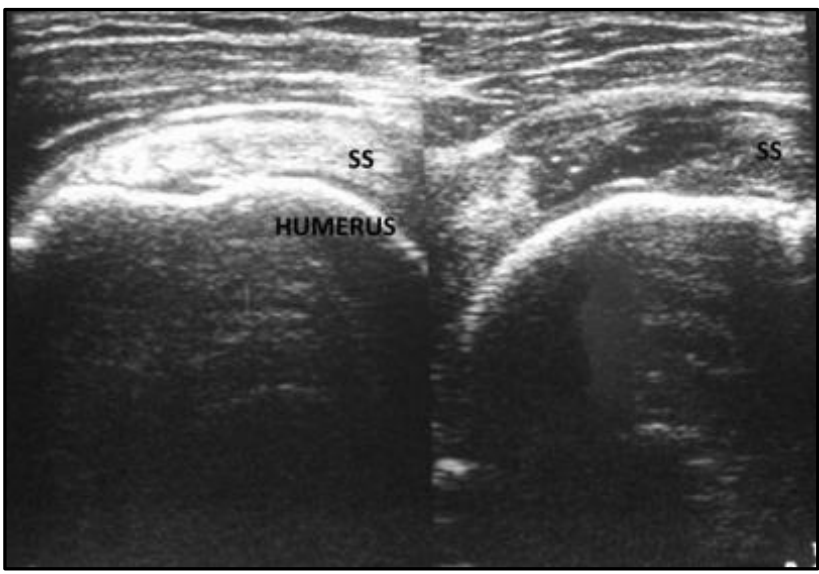

Figure 3. USG-Comparison of both Shoulders in a Patient-Normal SS on the Left and SS Partial Thickness Tear on the Right

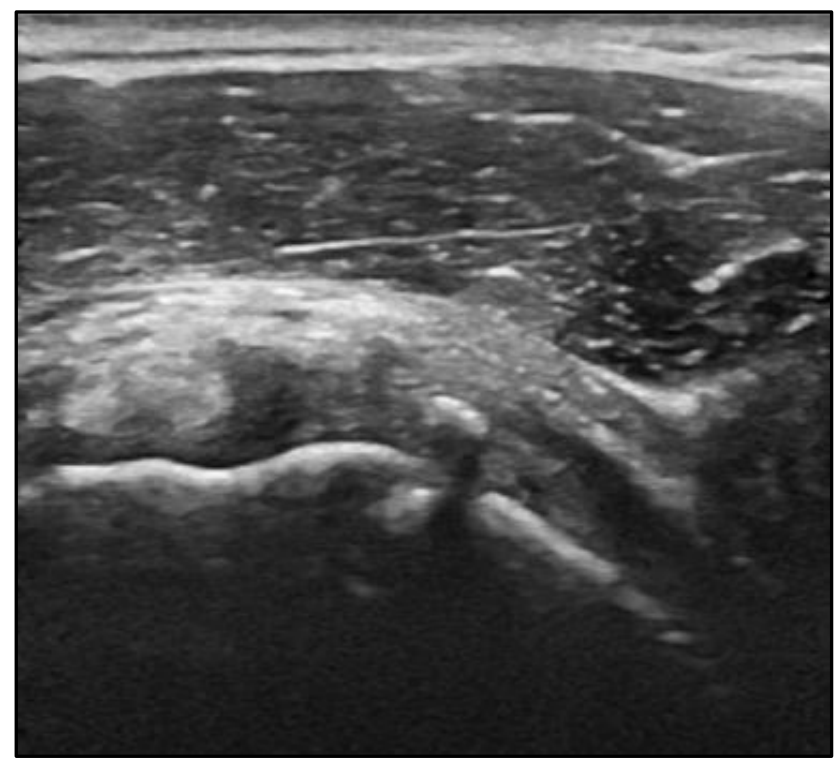

Figure 4. USG Supraspinatus Tendon showing Heterogeneity of Tendon with Calcificationa Case of Calcific Tendinitis

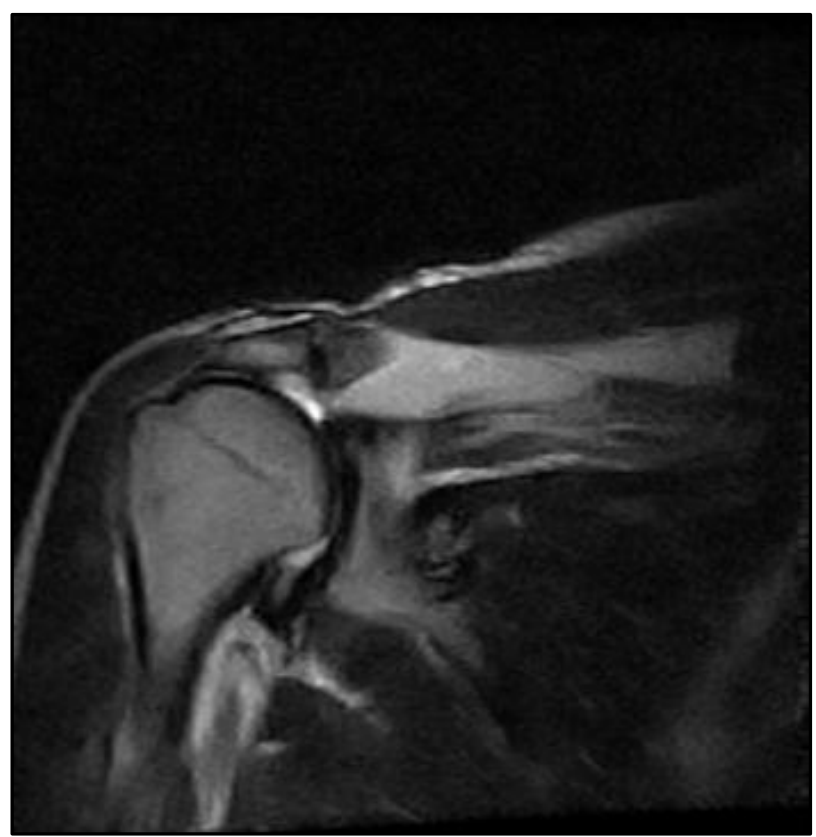

Figure 5. MRI Coronal T2WI showing Complete Tear of Supraspinatus Tendon

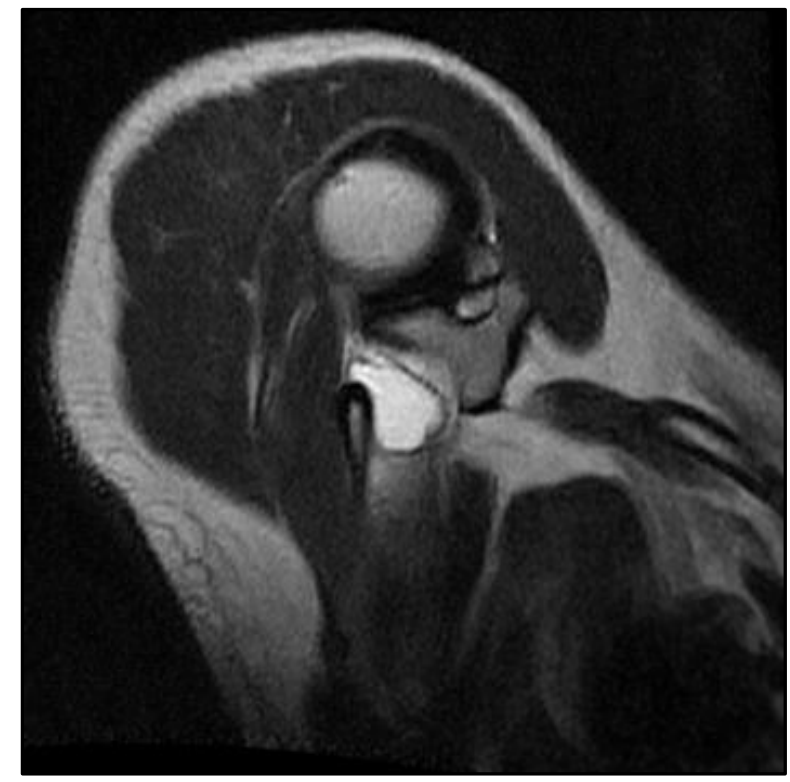

Figure 6. MRI Axial T2WI showing Spinoglenoid Notch Cyst

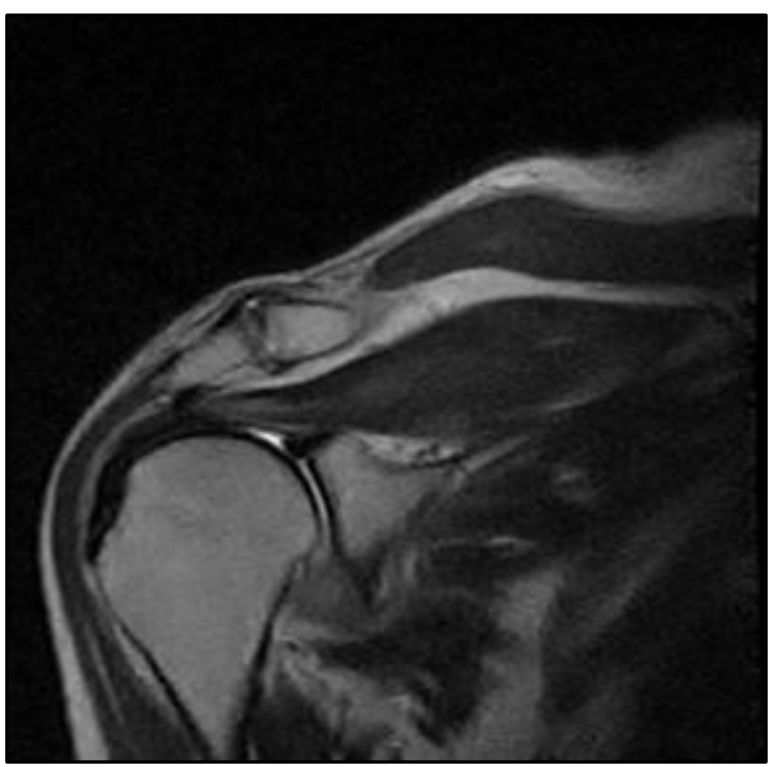

Figure 7. MRI T2 WI, STIR Coronal showing Hyperintensity in the Supraspinatus Tendon-S/O Tendinosis

\section{DISCUSSION}

A prospective study of 50 patients with shoulder pain with a clinical suspicion of rotator cuff tear was undertaken. USG examination of the affected shoulder was done in comparison with the normal shoulder and the findings were correlated with the subsequent MRI findings.

\section{Age Group Wise Incidence}

The age group of the study was from 21 - 80 years with maximum number of patients being of the age between 40 60 years constituting $68 \%$ of the study population. Hiroshi Minagawa et $\mathrm{al}^{1}$ studied the prevalence of tears in general population and found that the prevalence in each decade was $0 \%$ in the $20 \mathrm{~s}$ to $40 \mathrm{~s}, 10.7 \%$ in the $50 \mathrm{~s}, 15.2 \%$ in the $60 \mathrm{~s}$, $26.5 \%$ in the 70 s and $36.6 \%$ in the 80 s, whereas in our study it was $8 \%$ in the $20 \mathrm{~s}, 14 \%$ in the 30 s, $30 \%$ in the 40 s, $38 \%$ in $50 \mathrm{~s}, 6 \%$ in $60 \mathrm{~s}, 4 \%$ in $70 \mathrm{~s}$. In their study, the prevalence increased with age in general population. In our study, the 
prevalence increased with age till the 50s and then declined. The discrepancy in the prevalence in our study is probably related to the selection bias as our study was on the symptomatic patients reaching the hospital, whereas the study done by Hiroshi Minagawa et al was on the general population in a village.

\section{Gender Distribution}

Of the 50 patients $34(68 \%)$ were males and the rest 16 $(32 \%)$ were females, indicating a male predominance. The number of males in the age groups from 21 - 80 were more than double the number of females in the same age group. The number of males were higher than the number of females in the age group from $21-70$, but in the age group from 71 80 the number of males and females were equal. This was similar to the prevalence study done by Hiroshi Minagawa et $\mathrm{al},{ }^{1}$ where the prevalence of tear was significantly greater in male than in female in the $50 \mathrm{~s}$ and $60 \mathrm{~s}$, but not in the $70 \mathrm{~s}$ and 80 s.

\section{Side of Pathology}

The number of patients with pathology on the right side was 30 accounting for $60 \%$ of the cases, whereas those with leftsided shoulder pathologies accounted for 20 (40\%) of the cases.

\section{Duration of Symptoms}

More than half of the cases (27 out of 50 patients- $54 \%$ ) had an acute history of less than 1 month before presenting for an USG examination; 19 (38\%) of the cases had a history of 1 - 6 months duration and only $4(8 \%)$ had a history of more than 6 months.

\section{Pathology}

Rotator cuff pathologies include partial, full thickness, intrasubstance tears and tendinosis. Supraspinatus tendon was the commonest tendon to be involved. USG detected 35 cases (70\%) patients and MRI detected 38 patients with supraspinatus tendon pathologies. This is comparable to the study by Zlatkin et al, ${ }^{2}$ wherein they found that supraspinatus tendon involvement was present in around $80 \%$ of their cases.

\section{Supraspinatus}

The sensitivity and specificity of USG in detection of supraspinatus pathologies were $92.11 \%$ and $100 \%$ respectively. The positive predictive value was $100 \%$ and negative predictive value was $80 \%$. Accuracy of the study was $94 \%$. Spearman correlation value of $p$ was $<0.001$ and Kappa coefficient was 0.848 indicating that the value obtained was almost perfect.

\section{Partial Thickness Tears}

In our study, sensitivity and specificity values for partial thickness tear of supraspinatus was $80 \%$ and $100 \%$.

Our study showed a high specificity of $100 \%$ for partial thickness tears. The specificity findings were comparable with the study done by Read, John W and Mark Perko, ${ }^{3}$ in which the specificity of ultrasound for partial thickness tears was $97 \%$. Similarly, our results for sensitivity of partial thickness tears were also comparable with the results of Rutten et $\mathrm{al}^{4}$ whose study showed a sensitivity of $89 \%$ for partial thickness tears on ultrasound compared with the $80 \%$ sensitivity in our study.

Cullen et $\mathrm{al}^{5}$ compared the ultrasound and surgical results obtained from 68 patients. In their study, ultrasound showed a sensitivity of $79 \%$ and specificity of $94 \%$ (Positive Predictive value $87 \%$ ) for partial-thickness tears, which was comparable with our study. They found that shoulder ultrasound in the hands of an experienced radiologist with the use of modern high-resolution equipment is highly sensitive in differentiating complete tears and partialthickness tears. Our results for partial thickness tears were comparable with the results of their study.

Van-Holsbeeck et $\mathrm{al}^{6}$ (Van-Holsbeeck Kolowich 1995) ${ }^{6}$ described that the sensitivity of US in depiction of partialthickness tears was $93 \%$ and specificity was $94 \%$. The positive predictive value was $82 \%$ and the negative predictive value was $98 \%$.

\section{Full Thickness Tears}

Sensitivity and specificity values for full thickness tear of supraspinatus were $100 \%$ and $95.35 \%$. The findings of our study were comparable with the study done by Read, John W ${ }^{3}$ and Mark Perko in 1998. They studied the findings in 42 consecutive surgical cases and compared them with the preoperative sonographic readings. Ultrasound detected all of the 10 full-thickness cuff tears identified at surgery (Sensitivity 1.0, specificity 0.97 ), but detected only 6 of 13 partial-thickness cuff tears (sensitivity 0.46 , specificity 0.97 ). They concluded that ultrasound is a sensitive and accurate method of identifying patients with full-thickness tears of the rotator cuff, extracapsular biceps tendon pathology or both. Similarly, our study showed a high sensitivity of $100 \%$ and specificity of $95.35 \%$ for full thickness tears.

Cullen et al ${ }^{5}$ showed a sensitivity of $89 \%$ and specificity of $100 \%$ (Positive Predictive value 100\%) for full-thickness tears using ultrasound. They showed a high specificity of $100 \%$, whereas in our study specificity was $95.35 \%$. This was attributable to the false positive cases of full thickness tears on ultrasound, which were proven to be partial thickness tears on MRI. There are pitfalls with ultrasound, which give rise to such false positive cases.

\section{Accuracy}

PPV, NPV for partial thickness and full thickness tears were $100 \%, 83.33 \%, 77.78 \%$ and $100 \%$ respectively.

In our study, the accuracy values for partial thickness and full thickness tears of supraspinatus were $90 \%$ and $96 \%$. This was comparable with the study done by Anastasia N. Fotiadou et al. ${ }^{7}$ Anastasia N. Fotiadou et al ${ }^{7}$ studied ninety-six patients with clinically suspected rotator cuff pathology using USG and MRI. The accuracy in the detection of full-thickness tears was $98 \%$ and $100 \%$ for ultrasonography and magnetic resonance imaging respectively. The accuracy in the detection of bursal or articular partial-thickness tears was $87 \%$ and $90 \%$ for ultrasonography and magnetic resonance imaging respectively. They concluded that in experienced hands, ultrasonography should be considered.

\section{Spearman Correlation and Kappa Statistic}

The tests of significance- the spearman correlation and the Kappa statistic values for partial thickness and full thickness tears were 0.800 (substantial association), 0.852 (almost 
perfect association) indicating that the values obtained are significant.

This was comparable with the study done by Shahnawaz Bashir et al. ${ }^{8}$ Shahnawaz Bashir et al ${ }^{8}$ studied 50 patients, out of which a total of 34 patients were diagnosed as having rotator cuff tears on ultrasound, while 16 patients were normal. When MRI examination was conducted in these patients it showed 38 cases of rotator cuff tears, while 12 patients were diagnosed as normal. The agreement between the two methods was assessed using Kappa coefficient. The strength of agreement between USG and MRI for the diagnosis of rotator cuff tears was found to be 'very good.'

\begin{tabular}{|c|c|c|c|c|c|c|c|c|c|c|}
\hline & \multicolumn{9}{c|}{ Our Study } & \multicolumn{1}{c|}{ Bashir Shahnawaz et al } \\
\hline Findings & TP & FP & FN & TN & Kappa Value & TP & FP & FN & TN & Kappa Value \\
\hline $\begin{array}{c}\text { Partial } \\
\text { Thickness }\end{array}$ & 20 & 0 & 5 & 25 & $\begin{array}{c}0.800 \\
\text { Substantial }\end{array}$ & 12 & 2 & 4 & 12 & 0.818 \\
\hline Full Thickness & 7 & 2 & 0 & 4 & 0.852 Almost Perfect & 20 & 0 & 2 & 12 & \\
\hline \multicolumn{19}{|c|}{ Table 11. Comparison of Kappa Values } \\
\hline
\end{tabular}

\section{Biceps Tendon}

The pathologies of biceps tendon in our study included tendinosis alone with no case of tear/dislocation. Sensitivity and specificity values for Biceps tendon pathologies were $66.67 \%$ and $97.87 \%$, which were comparable with that of the study done by Shih-Wei et al. ${ }^{9}$

Shih-Wei Huang et $\mathrm{al}^{9}$ studied a total of 336 shoulder pain patients with suspected biceps tendinitis, of which a total of 136 patients were classified with biceps tendinitis and 200 patients were classified as not having biceps tendinitis based on the diagnostic criteria. The sensitivity was $68 \%$ and the specificity was $90 \%$ in the standard deviation of the transverse view, and the sensitivity was $81 \%$ and the specificity was $73 \%$ in the standard deviation of the longitudinal view to diagnose biceps tendinitis.

PPV of $66.67 \%$, NPV of $97.87 \%$, accuracy of $96 \%$, p value of spearman correlation $<0.001$, significant and Kappa coefficient was 0.645 suggesting a substantial association.

\section{Subscapularis}

Sensitivity and specificity values for subscapularis pathologies was $50 \%$ and $97.92 \%$, PPV of $50 \%$, NPV of $97.92 \%$, accuracy of $94 \%, \mathrm{p}$ value of spearman correlation $<0.001$, significant and Kappa coefficient was 0.315 suggesting a fair association.

\section{Infraspinatus and Teres Minor}

No pathology of infraspinatus and teres minor was observed on either USG or MRI giving them the specificity, negative predictive value and accuracy of $100 \%$.

\section{Peribicipital Tendon Fluid}

Sensitivity and specificity values for peribicipital fluid was $51.28 \%$ and $100 \%$, PPV of $100 \%$, NPV of $36.67 \%$, accuracy of $62 \%, p$ value of spearman correlation 0.012 , significant and Kappa coefficient was 0.317 suggesting a fair association.

\section{Subacromial Subdeltoid Bursitis}

Sensitivity and specificity values for subacromial, subdeltoid bursitis was $25 \%$ and $86.36 \%$, PPV of $70 \%$, NPV of $47.5 \%$, accuracy of $52 \%$, p value of spearman correlation 0.119 , nonsignificant and Kappa coefficient was 0.104 suggesting a slight association. Therefore, for detection of peribicipital fluid and subacromial subdeltoid bursitis, MRI is the preferred modality over USG as ultrasound has very low sensitivity.

Four cases had calcifications on ultrasound and only one of them observed on MRI.
Ultrasound can be used for the initial investigation of suspected rotator cuff pathologies. Advantages of ultrasound are non-invasive, real time, low cost, no radiation and the advantage of dynamic examination and comparison with the normal side. However, it has the following pitfalls.

The pitfalls in ultrasound evaluation of rotator cuff pathologies on shoulder include those related to anisotropy, calcific tendinitis complex anatomy in the region of the rotator interval and tendinous interdigitation.

- The rotator cuff appears echogenic when the angle of insonation is perpendicular or near perpendicular to the surface. Minor deviation from this orientation results in a false positive appearance of a tear.

- Intratendinous deposition of calcium is manifested by both focal echogenicity and acoustical shadowing. Failure to recognise these coexistent findings may result in inadvertent misinterpretation of the hypoechoic, shadowing zone as a rotator cuff tear.

- The rotator interval, which is normally devoid of cuff tissue may be mistaken for a rotator cuff defect.

- The edge of the intraarticular biceps tendon may be mistaken for a torn and retracted cuff tear. The hypoechoic interface between the biceps and adjacent supraspinatus tendons may simulate a longitudinal cuff tear.

- Heterogeneity of the normal rotator cuff can be normally observed, because of the complex interdigitation of fibres from the various contributions.

- Steep learning curve and interobserver variation in results.

Even MRI has its own Limitations and Pitfalls-

The limitations are claustrophobia, obese patients, postsurgical metallic implant fixations.

Pitfalls of MR imaging include the magic angle effect and normal fibre interdigitation. Tendons that course at or near the magic angle of $55^{\circ}$ exhibit markedly augmented signal intensity that is most pronounced with short-echo-time sequences. The supraspinatus tendon is particularly vulnerable, since it curves along its course between the musculotendinous junction and its insertion on fibrocartilage. Furthermore, magic angle augmentation of signal intensity within the biceps tendon may be misinterpreted as focal cuff pathologic conditions near the rotator interval. The complex arrangement of rotator cuff fibres is frequently manifested by striations that may be mistaken for intrasubstance tears. 


\section{CONCLUSION}

In our study of 50 patients with suspected rotator cuff pathology, ultrasound demonstrated a high sensitivity and specificity more so for supraspinatus tendon pathologies and least for peribicipital tendon fluid collection and SASD bursitis. Also, USG is a reliable dynamic diagnostic tool and provides direct correlation of the imaging findings with the symptoms of the patient, and helps with guided interventional procedures. Therefore, it should be considered as an accurate modality for the initial investigation of rotator cuff, especially supraspinatus tears. MRI is preferably done after sonography in doubtful cases or for evaluation of other pathologies of the shoulder joint like labral pathologies.

\section{REFERENCES}

[1] Minagawa H, Yamamoto N, Abe H, et al. Prevalence of symptomatic and asymptomatic rotator cuff tears in the general population: From mass-screening in one village. J Orthop 2013;10(1):8-12.

[2] Zlatkin MB, Iannotti JP, Roberts MC, et al. Rotator cuff tears: diagnostic performance of MRI. Radiology 1989;172(1):223-9.

[3] John RW, Perko M. Shoulder ultrasound: diagnostic accuracy for impingement syndrome, rotator cuff tear, and biceps tendon pathology. Journal of Shoulder and Elbow Surgery 1998;7(3):264-271.
[4] Rutten MJ, Spaargaren GJ, van Loon T, et al. Detection of rotator cuff tears: the value of MRI following ultrasound. European Radiology 2010;20(2):450-7.

[5] Cullen DM, Breidahl WH, Janes GC. Diagnostic accuracy of shoulder ultrasound performed by a single operator. Australas Radiol 2007;51(3):226-9.

[6] van Holsbeeck MT, Kolowich PA, Eyler WR, et al. US depiction of partial-thickness tear of the rotator cuff. Radiology 1995;197(2):443-6.

[7] Vlychou M, Dailiana Z, Fotiadou A, et al. Symptomatic partial rotator cuff tears: diagnostic performance of ultrasound and magnetic resonance imaging with surgical correlation. Acta Radiol 2009;50(1):101-5.

[8] Bashir S, Firdose SR, Kamal Y, et al. Correlation between high resolution ultrasonography and MRI in rotator cuff tear diagnosis. International Journal of Health Sciences and Research (IJHSR) 2014;4(8): 103-12.

[9] Huang SW, Wang WT. Quantitative diagnostic method for biceps long head tendinitis by using ultrasound. The Scientific World Journal 2013;2013:948323. 